\title{
Anatomia comparada do lenho de Copaifera langsdorffii Desf. (Leguminosae-Caesalpinoideae) de floresta e cerradão
}

\author{
CARMEN REGINA MARCATI ${ }^{1,4}$, VERONICA ANGYALOSSY-ALFONSO ${ }^{2} \mathrm{e}$ \\ LUCIMAR BENETATI $^{3}$
}

(recebido: 20 de setembro de 2000; aceito: 13 de junho de 2001)

\begin{abstract}
Comparative wood anatomy of Copaifera langsdorffii Desf. (Leguminosae-Caesalpinoideae) in forest and "cerradão"). The present study compares qualitative and quantitative characters of the wood of a tree species (Copaifera langsdorffii Desf.-Leguminosae-Caesalpinoideae) from semideciduous mesophytic forest and "cerradão". Analysis revealed vessels with significantly larger diameter in trees from "cerradão" and intervascular pits being significantly larger in trees from forest. In contrast to the trees from the forest, gelatinous fibers, which have a special layer innermost of the wall, were found in great quantity in trees from "cerradão". Furthermore, the presence of subdivided marginal parenchyma and the absence of axial canals in some of the parenchyma bands are for the first time mentioned for this species.
\end{abstract}

RESUMO - (Anatomia comparada do lenho de Copaifera langsdorffii Desf. (Leguminosae-Caesalpinoideae) de floresta e cerradão). O presente estudo compara a estrutura do lenho de uma espécie arbórea (Copaifera langsdorffii Desf.) que ocorre em floresta mesófila semidecídua e em cerradão. Objetivou-se verificar diferenças estruturais qualitativas e quantitativas nos espécimes em relação aos dois ecossistemas. A análise estatística revelou um maior diâmetro tangencial dos vasos nos espécimes do cerradão e um maior diâmetro tangencial das pontoações intervasculares nos espécimes da floresta, ambos ao nível de 0,05. Fibras gelatinosas foram encontradas em maior quantidade nos espécimes do cerradão quando comparadas com os espécimes da floresta. A presença de um parênquima marginal que se subdivide e algumas faixas parenquimáticas que não apresentam canais axiais são pela primeira vez mencionadas em Copaifera langsdorfii.

Key words - Anatomy, wood anatomy, Copaifera langsdorffii

\section{Introdução}

Os trabalhos que comparam floras ou espécies em diferentes ambientes de regiões temperadas e/ou tropicais têm demonstrado que as variações ambientais refletem em variações estruturais do lenho, principalmente quanto às dimensões dos elementos celulares, tais como: diâmetro, comprimento e freqüência de vasos, espessura da parede e comprimento de fibras, altura e largura de raios (Baas et al. 1983, Carlquist \& Hoekman 1985, Baas \& Carlquist 1985, Barajas-Morales 1985, Baas \& Schweingruber 1987).

1. Universidade Estadual Paulista, Faculdade de Ciências Agronômicas, Departamento de Recursos Naturais/Ciências Florestais, Campus de Botucatu, Caixa Postal 237, 18603-970 Botucatu, SP, Brasil.

2. Universidade de São Paulo, Instituto de Biociências, Departamento de Botânica, Caixa Postal 11461, 05422-970 São Paulo, SP, Brasil.

3. Universidade de Santo Amaro, Departamento de Biologia, 04829-300 São Paulo, SP, Brasil.

4. Autor para correspondência: carmen@ @ fca.unesp.br
Na década de 70 surgiram as primeiras pesquisas em anatomia da madeira, enfocando aspectos ecológicos, sendo Baas (1973) e Carlquist (1975) considerados os pioneiros.

No Brasil, o primeiro trabalho sobre anatomia ecológica do lenho foi o de Mina-Rodrigues (1986), que comparou a morfologia e anatomia dos órgãos vegetativos de Pera glabrata (Euphorbiaceae) em ambiente de floresta mesófila semidecídua e em cerrado. A autora verificou variações na morfologia externa e interna da árvore. Nesta mesma linha, Ceccantini (1996) constatou diferenças qualitativas e quantitativas nas estruturas anatômicas de duas espécies em região de cerrado e de floresta estacional semidecídua. $\mathrm{O}$ autor concluiu que as características do lenho mais sensíveis às variações ambientais são o diâmetro e a frequiência de vasos e o comprimento das fibras.

Uma análise ampla quanto às variações anatômicas das espécies em relação ao ambiente foi realizada por Alves \& Angyalossy-Alfonso (2000), através do estudo de 22 famílias mais representativas da flora brasileira, abrangendo 133 gêneros e cerca de 490 espécies. As autoras verificaram algumas 
tendências relacionadas a fatores ambientais, estatisticamente comprovadas, para arranjo e agrupamento dos vasos e camadas de crescimento, sendo que as tendências relacionadas à latitude foram mais claras que aquelas relativas aos demais parâmetros ambientais, como: clima, temperatura, umidade, vegetação e altitude.

Mesmo considerando que há um número relativamente grande de espécies cujo lenho foi estudado com o enfoque ecológico, ainda assim podese dizer que este número é pequeno quando se considera a riqueza de espécies da flora brasileira.

Este trabalho tem como objetivos caracterizar anatomicamente o lenho de Copaifera langsdorffii Desf. em floresta mesófila semidecídua e cerradão e diagnosticar diferenças estruturais qualitativas e quantitativas do lenho em relação aos dois ecossistemas.

\section{Material e métodos}

O trabalho foi desenvolvido em floresta classificada, segundo Rizzini (1976), em Floresta Mesófila Semidecídua, que pertence à Fazenda Experimental Edgardia da Faculdade de Ciências Agronômicas da Universidade Estadual Paulista, UNESP, de Botucatu, e apresenta, segundo Carvalho et al. (1991), área de 1200,32 ha, tendo área florestal com superfície total de 1000 ha. Suas coordenadas geográficas são $20^{\circ} 50$ '00"$22^{\circ} 47^{\prime} 30^{\prime \prime} \mathrm{S}$ e $48^{\circ} 26^{\prime} 15^{\prime}$ '-48²2'30" W. Vários tipos de solos são encontrados nesta área, sendo que a espécie em estudo encontra-se no solo do tipo areias quartzozas (Carvalho et al. 1991). O tipo de clima, segundo a classificação de Köeppen (1931), é Cwb (mesotérmico de inverno seco).

O cerradão é uma área de transição entre cerrado e floresta e está localizado na Fazenda Gold Farm, 22 $48^{\prime} 00^{\prime}$ S e $48^{\circ} 17^{\prime} 5^{\prime}$ " W. Os solos são do tipo podzolico vermelho amarelo, profundos, de textura muito leve, acentuadamente arenosos com pequena capacidade de retenção de água, ácidos e de baixa fertilidade. Sua vegetação é constituída por árvores de até $12 \mathrm{~m}$ de altura em média, com estrato arbustivo e subarbustivo bastante denso (Bicudo et al. 1996).

Dez espécimes de Copaifera langsdorffii Desf. foram selecionados para o estudo, sendo cinco pertencentes a floresta e cinco ao cerradão. Todos os espécimes coletados apresentam-se em fase adulta e estão localizados próximos entre si, evitando assim, dentro do mesmo ambiente, alterações estruturais em função da variabilidade de solo, temperatura, umidade relativa e precipitação. Evitou-se também grande variação do porte dos indivíduos, mesmo entre os dois ambientes.

De cada espécime foi coletada uma amostra à altura do peito $(1,30 \mathrm{~m}$ do solo), com aproximadamente $7 \mathrm{~cm} \mathrm{de}$ largura, $5 \mathrm{~cm}$ de altura e profundidade dependendo da espessura da casca, com auxílio de formão e serra de arco.

As amostras do lenho foram depositadas na xiloteca do Departamento de Botânica do Instituto de Biociências da Universidade de São Paulo $\left(\mathrm{SPF}_{\mathrm{w}}\right)$. As informações quanto ao coletor, número de coleção, diâmetro à altura do peito e altura de cada árvore coletada encontram-se na tabela 1 .

Do material coletado foram retirados fragmentos com cerca de $1,5 \mathrm{~cm}^{3}$, que foram amolecidos e então seccionados em micrótomo de deslize para obtenção dos cortes histológicos. Nestes, as colorações utilizadas foram: azul de astra $0,5 \%$ em ácido tartárico $2 \%$ e acroidina-crisoidina $0,5 \%$ aquoso (Kropp 1972).

A fixação dos corantes foi feita com acetato de butila e lâminas histológicas foram montadas permanentemente em Bálsamo do Canadá. A dissociação de células seguiu a proposta de Franklin (1945).

Os dados quantitativos foram obtidos das seguintes características: diâmetro e comprimento de elementos de vasos e fibras, diâmetro de pontoações inter e radiovasculares, freqüência de vasos, altura e largura dos raios. Para as quantificações utilizou-se um microscópio de luz, e os valores obtidos foram convertidos em micrometros através de um fator de conversão. Para a obtenção da frequiência de vasos utilizou-se um microscópio adaptado para projeção.

O número de medições foi fixado em $\mathrm{n}=10$ para diâmetro tangencial de pontoação, seguindo as recomendações do IAWA Committee (1989); para os demais parâmetros foi fixado um $\mathrm{n}=30$. Para comparação entre as médias dos dois ambientes aplicou-se o teste de Tukey para todas as variáveis quantificadas.

Tabela 1. Espécimes de Copaifera langsdorffii analisados anatomicamente. DAP = diâmetro à altura do peito.

\begin{tabular}{clccc}
\hline Ambiente & $\mathrm{N}^{\mathrm{o}}$ Coletor & $\mathrm{N}^{\mathrm{o}}$ Xiloteca $\left(\mathrm{SPF}_{\mathrm{w}}\right)$ & $\mathrm{DAP}(\mathrm{cm})$ & Altura $(\mathrm{m})$ \\
\hline & C.R. Marcati 1 & 829 & 70 & 15 \\
& C.R. Marcati 2 & 830 & 76 & 13 \\
Floresta Mesófila Semidecídua & C.R. Marcati 3 & 831 & 71 & 15 \\
& C.R. Marcati 4 & 854 & 60 & 20 \\
& C.R. Marcati 5 & 855 & 65 & 20 \\
\hline \multirow{3}{*}{ Cerradão } & C.R. Marcati 6 & 832 & 43 & 15 \\
& C.R. Marcati 7 & 833 & 33 & 12 \\
& C.R. Marcati 8 & 834 & 45 & 13 \\
& C.R. Marcati 9 & 856 & 31 & 11 \\
& C.R. Marcati 10 & 857 & 33 & 15 \\
\hline
\end{tabular}


A terminologia adotada para a análise anatômica segue aquela estabelecida pelo IAWA Committee (1989).

\section{Resultados e Discussão}

Qualitativamente, os espécimes da floresta e do cerradão não variaram em relação aos ambientes analisados, diferindo apenas quanto a distribuição das fibras gelatinosas. A seguir são analisadas as características marcantes da espécie em ambos os ambientes.

Os espécimes apresentaram camadas de crescimento distintas, delimitadas por faixas de parênquima marginal, umas distribuindo-se em intervalos regulares e outras que se distanciam em intervalos menores (figuras 1, 10).

Nos representantes dos dois ambientes estudados, os vasos solitários são os predominantes (61\%) em relação aos vasos múltiplos de dois (19\%), ocorrendo ainda múltiplos de três a raros múltiplos de dez (figuras 1,10), com freqüência média de sete vasos por $\mathrm{mm}^{2}$. Mainieri \& Chimelo (1989) registraram $70 \%$ dos vasos solitários para a mesma espécie. A presença de vasos solitários e múltiplos, segundo
Alves \& Angyalossy-Alfonso (2000), é a situação mais comum dentro da flora brasileira.

$\mathrm{O}$ arranjo difuso dos vasos foi observado tanto para os indivíduos da floresta quanto para os indivíduos do cerradão. Segundo Alves \& Angyalossy-Alfonso (2000), entre as angiospermas tropicais, este tipo de arranjo é o mais freqüente, porém as autoras não encontraram evidências estatísticas que permitam relacionar este fato com os parâmetros ambientais.

Constatou-se a presença de elementos de vaso com e sem apêndices e esses, quando presentes, se encontram em uma ou em ambas as extremidades (figura 4). As pontoações intervasculares são alternas, areoladas, guarnecidas e com abertura inclusa (figuras 5, 6). As pontoações radiovasculares são semelhantes às intervasculares.

A presença de pontoações guarnecidas é uma característica da família Leguminosae. Alves \& Angyalossy-Alfonso (2000) constataram fortes indicações da existência de relação entre pontoações guarnecidas e ambientes secos. Segundo Carlquist (1982, 1983, 1988), as guarnições têm um papel importante na prevenção de embolias aumentando a

Tabela 2. Dados quantitativos dos elementos celulares do lenho de Copaifera langsdorffii nos ambientes de floresta mesófila semidecídua (FLO) e cerradão (CER). Diferenças significativas ao nível de 5\% (teste Tukey).

\begin{tabular}{|c|c|c|c|c|}
\hline Parâmetro & Ambiente & $\overline{\mathrm{X}}$ geral & $\mathrm{F}$ & $\mathrm{CV}(\%)$ \\
\hline Freqüência de vaso $\left(\mathrm{n}^{\circ} \mathrm{mm}^{-2}\right)$ & $\begin{array}{l}\text { FLO } \\
\text { CER }\end{array}$ & $\begin{array}{l}7 \mathrm{a} \\
7 \mathrm{a}\end{array}$ & 0,02 & 40 \\
\hline Diâmetro do vaso $(\mu \mathrm{m})$ & $\begin{array}{l}\text { FLO } \\
\text { CER }\end{array}$ & $\begin{array}{l}137 \mathrm{a} \\
150 \mathrm{~b}\end{array}$ & 26,02 & 16 \\
\hline Comprimento do vaso $(\mu \mathrm{m})$ & $\begin{array}{l}\text { FLO } \\
\text { CER }\end{array}$ & $\begin{array}{l}373 a \\
388 a\end{array}$ & 2,75 & 21 \\
\hline Diâmetro da fibra $(\mu \mathrm{m})$ & $\begin{array}{l}\text { FLO } \\
\text { CER }\end{array}$ & $\begin{array}{l}10 \mathrm{a} \\
11 \mathrm{a}\end{array}$ & 0,89 & 42 \\
\hline Diâmetro tangencial da fibra $(\mu \mathrm{m})$ & $\begin{array}{l}\text { FLO } \\
\text { CER }\end{array}$ & $\begin{array}{l}23 a \\
23 a\end{array}$ & 0,00 & 18 \\
\hline Comprimento da fibra $(\mu \mathrm{m})$ & $\begin{array}{l}\text { FLO } \\
\text { CER }\end{array}$ & $\begin{array}{l}963 a \\
973 a\end{array}$ & 0,12 & 26 \\
\hline Largura do raio $(\mu \mathrm{m})$ & $\begin{array}{l}\text { FLO } \\
\text { CER }\end{array}$ & $\begin{array}{l}43 a \\
44 a\end{array}$ & 0,85 & 30 \\
\hline Diâmetro intervascular pontoação $(\mu \mathrm{m})$ & $\begin{array}{l}\text { FLO } \\
\text { CER }\end{array}$ & $\begin{array}{r}10 \mathrm{a} \\
9 \mathrm{~b}\end{array}$ & 6,75 & 18 \\
\hline Diâmetro radiovascular pontoação $(\mu \mathrm{m})$ & $\begin{array}{l}\text { FLO } \\
\text { CER }\end{array}$ & $\begin{array}{l}9 a \\
9 a\end{array}$ & 0,01 & 30 \\
\hline
\end{tabular}

$\overline{\mathrm{X}}$ geral = média total para o ambiente. Médias com a mesma letra não diferem significativamente; médias com letras diferentes diferem significativamente; $\mathrm{F}=$ valor do teste $\mathrm{F}$ da análise de variância; $\mathrm{CV}=$ coeficiente de variação. 

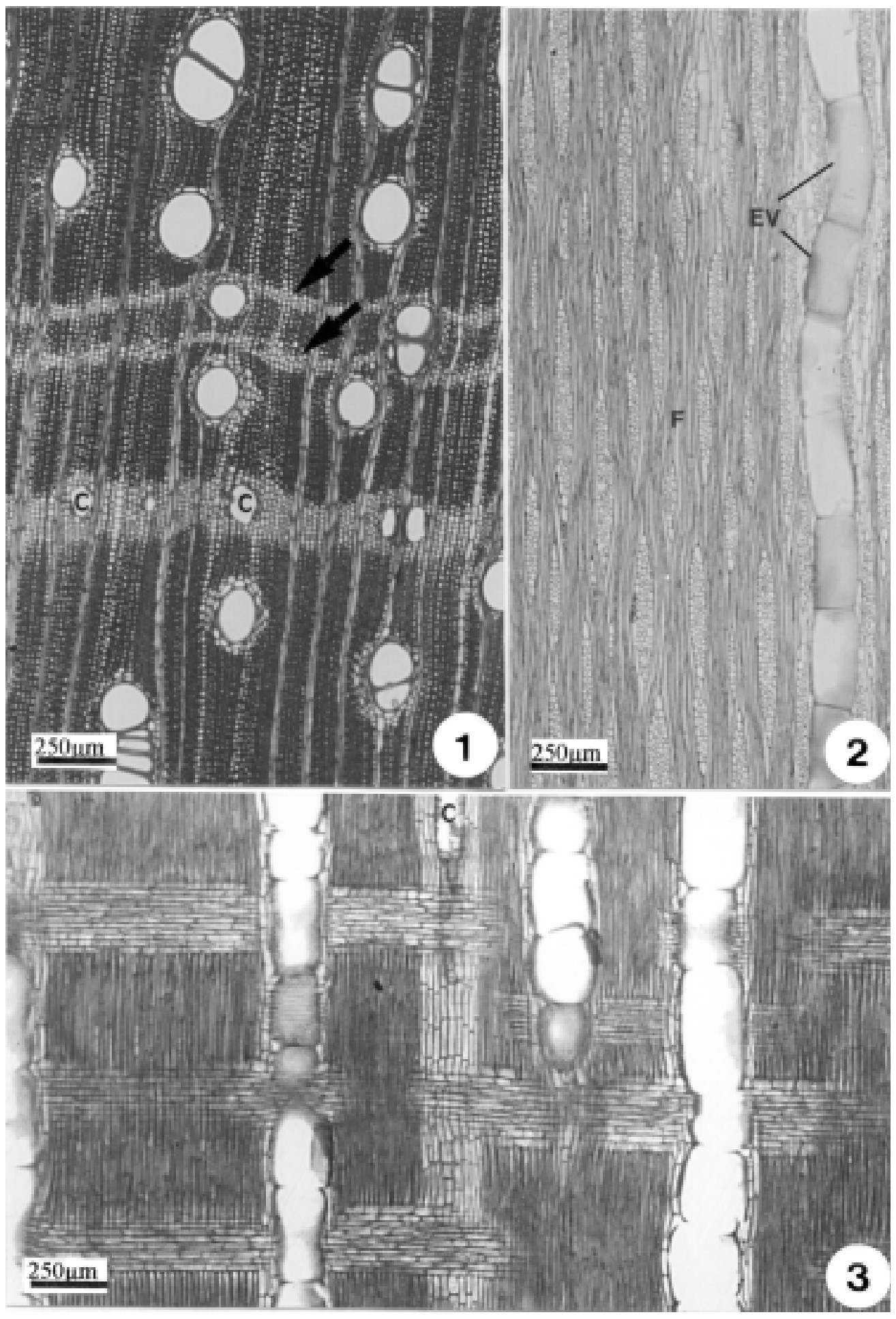

Figuras 1-3. Copaifera langsdorffii que ocorre em floresta mesófila semidecídua. 1. Seção transversal. Camada de crescimento demarcada por faixa de parênquima marginal, com canais axiais (C) e sem canais axiais (setas). Porosidade difusa. Parênquima axial vasicêntrico escasso. Vasos solitários e múltiplos. 2. Seção tangencial. Elementos de vaso (EV). Fibras (F). 3. Seção radial. Raio heterogêneo: células quadradas e células procumbentes. Canal axial (C). 

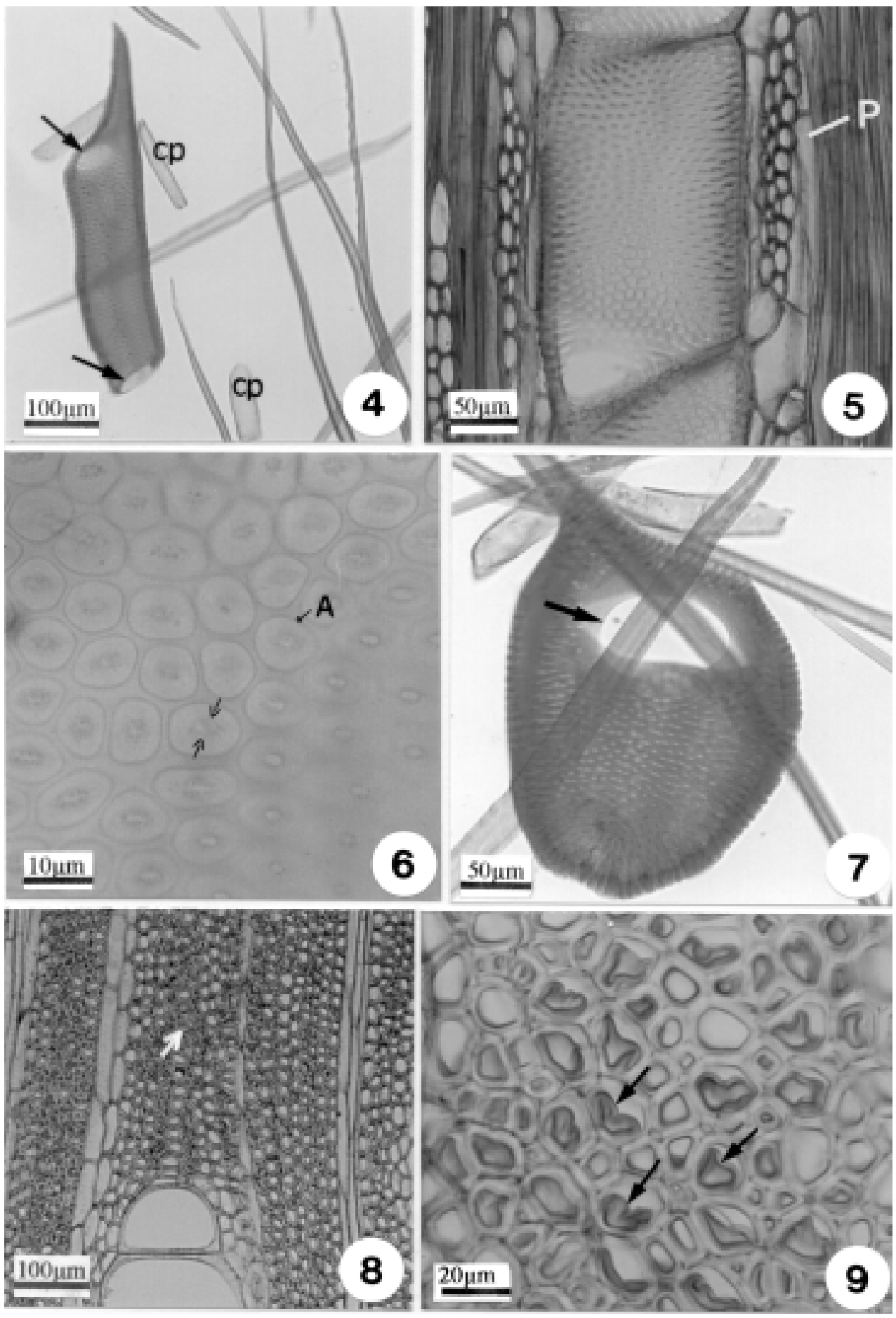

Figuras 4-9. Copaifera langsdorffii que ocorre em cerradão. 4. Células dissociadas. Elemento de vaso com apêndice e placas de perfuração simples (setas). Células parenquimáticas (cp). Fibras libriformes. 5-6. Seções tangenciais. 5. Elemento de vaso com pontoações intervasculares alternas. Célula do parênquima axial (P). 6. Detalhe das pontoações intervasculares com aréolas evidentes (A), guarnecidas e abertura inclusa (setas). 7. Células dissociadas. Elemento de vaso com placa de perfuração simples (seta). 8-9. Seções transversais. 8. Fibras gelatinosas (seta). 9. Detalhe das fibras gelatinosas com a camada gelatinosa, celulósica, mais interna, que se desprende do restante da parede secundária por artefato (setas). 
aderência das moléculas de água à parede das células. Assim, as pontoações guarnecidas seriam adaptativas a ambientes que sofrem algum tipo de estresse hídrico, como o confirmado por Machado et al. (1997), em espécie de cerrado, Styrax camporum, que apresenta pontoações guarnecidas na raiz.

Placas de perfuração simples foram encontradas nos indivíduos da floresta e do cerradão (figuras 4 , 7), característica também comum à família Leguminosae. Segundo Wheeler (1986), o lenho da maioria das espécies arbóreas (80\%) possui placa de perfuração simples. Para a flora brasileira, Alves \& Angyalossy-Alfonso (2000), registraram placas de perfuração simples na madeira de $95 \%$ das espécies estudadas e relacionaram este tipo de placa com ambientes secos e quentes. Machado et al. (1997) encontraram, para espécie do cerrado, Styrax camporum, placas de perfuração predominantemente simples nas raízes e escalariformes no caule e sugerem que este fato seja uma situação de adaptação às condições do ambiente. Wheeler \& Baas (1991) consideram também que as placas de perfuração simples sejam mais eficientes quanto à demanda do intenso fluxo de água, imposta pelas altas taxas de transpiração, em regiões secas e quentes.

As fibras são libriformes, sendo algumas do tipo gelatinosas (figuras 8, 9). Estas últimas apresentam paredes internas espessadas de constituição celulósica, que devido a artefato de técnica se destacam da parede lignificada, o que facilita sua observação (figuras 8,9). As fibras gelatinosas estão presentes em maior quantidade e distribuídas de forma particular nos indivíduos do cerradão. Neste, dentro de uma mesma camada de crescimento, fibras gelatinosas com paredes espessadas e lume reduzido, são observadas próximas à faixa de parênquima que delimita a camada de crescimento, e fibras gelatinosas com paredes mais delgadas e lume maior, distantes desta faixa parenquimática. Nos indivíduos da floresta, as fibras gelatinosas também estão presentes, porém em menor quantidade e de forma aleatória no interior da camada de crescimento. Esau (1974) relaciona estas fibras à presença do lenho de tração nas folhosas, o que está relacionado à tortuosidade do tronco. Paviani (1978), verificou a presença de fibras gelatinosas nos sistemas subterrâneos de espécies do cerradão. A autora admite que essas fibras tenham função de reserva de água devido a marcante presença da celulose que é hidrófila. As fibras gelatinosas observadas nos indivíduos da Copaifera langsdorffii do cerradão provavelmente não estão relacionadas ao lenho de tração, pois os espécimes estudados têm o fuste reto. Como no cerradão a retenção hídrica é menor quando comparada a da floresta (Rizzini 1976), acredita-se que estas fibras possam estar relacionadas com o armazenamento de água, conforme o observado por Paviani (1978).

Para os dois ambientes estudados, a espécie apresenta parênquima axial vasicêntrico escasso (figuras 1, 10) e também parênquima axial em faixas marginais com mais de 3 células de largura. Estas faixas marginais contém, na sua maioria, canais axiais normais (figura 1) e delimitam as camadas de crescimento. Além destas faixas, ocorrem também outras que se subdividem e não apresentam canais axiais (figura 10), o que não foi descrito para a espécie na literatura consultada (Détienne \& Jacquet 1983, Mainieri \& Chimelo 1989, Jankowsky et al. 1990).

Os canais axiais estão presentes somente na faixa marginal (figuras 1,10 ) e se originam à partir do afastamento de células parenquimáticas (figuras 1719). Inicialmente, as células parenquimáticas envolvidas na formação dos canais encontram-se justapostas (figura 17). O processo de separação das células é evidenciado pela formação de uma pequena cavidade (figuras 14, 18) que progride (figuras 15, 19), dando origem a espaços intercelulares grandes (figuras 16, 19, 20) e longos (figura 3), caracterizando um canal axial secretor. As células de parede primária, que delimitam o canal secretor, correspondem às células epiteliais, que são principalmente axiais (figuras 17-20) e eventualmente radiais. Segundo Esau (1974), de acordo com a origem, os canais axiais podem ser classificados em três categorias: lisígenos, quando a formação da cavidade é resultante da dissolução de células parenquimáticas; esquizógenos, quando a formação é devido a separação das células; e esquizo-lisígenos que representa a combinação das duas categorias anteriores. De acordo com esta classificação, os canais axiais observados nesta espécie enquadram-se no tipo esquizógeno. Segundo Record \& Hess (1943), estes canais, que ocorrem em todas as espécies do gênero Copaifera, produzem goma ou óleo conhecido no comércio como óleo de copaíba, sendo usado como ingrediente medicinal, verniz em trabalhos artesanais, e também pelos índios para passar sobre seus corpos e cabelos com propósitos medicinais. 

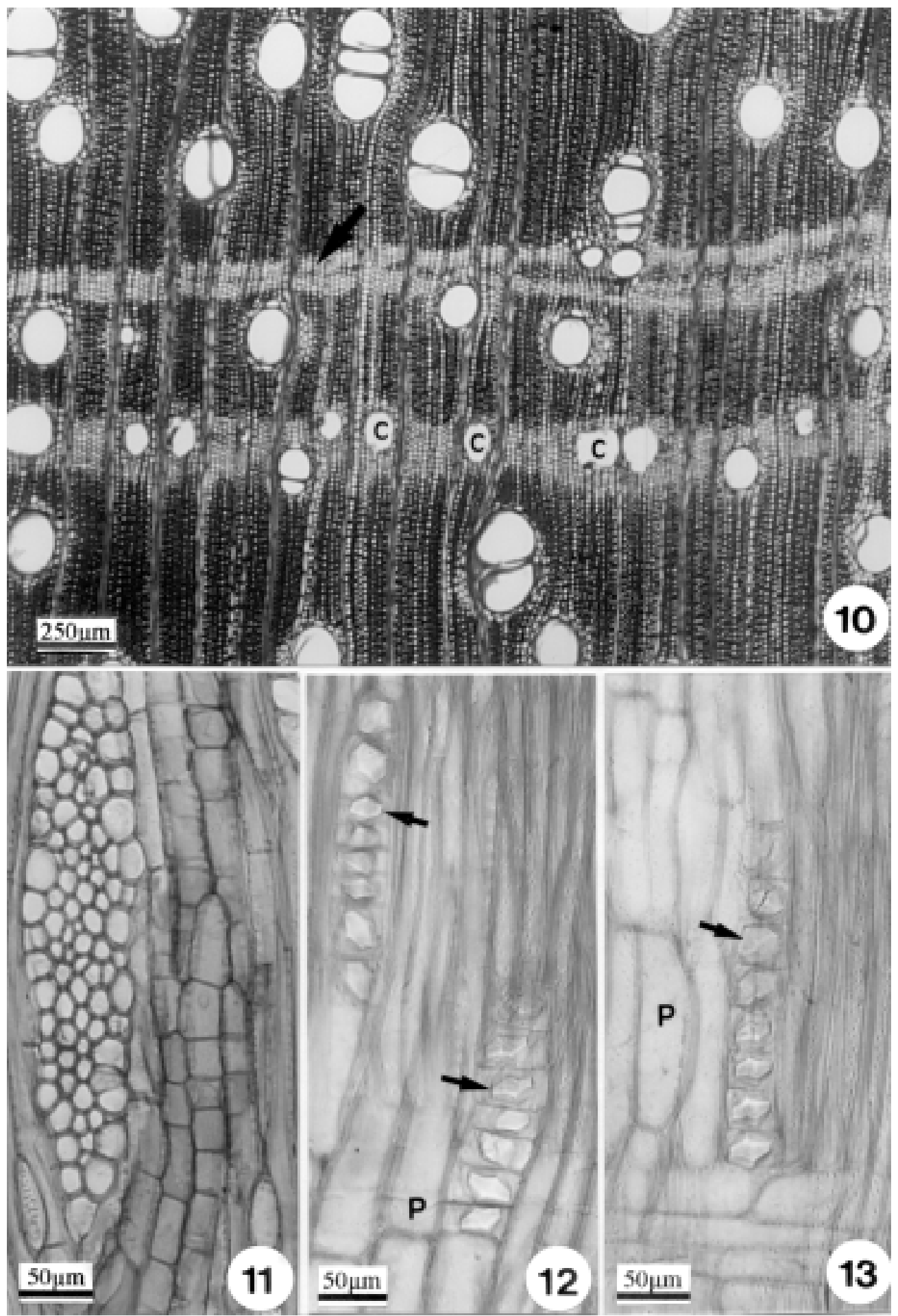

Figuras 10-13. Copaifera langsdorffii que ocorre em floresta mesófila semidecídua. 10. Seção transversal. Faixa de parênquima marginal que se subdivide, sem canais axiais (seta) e faixa de parênquima marginal com canais axiais (C). 11. Seção tangencial. Células parenquimáticas subdivididas. 12-13. Seções radiais. Células de parênquima axial (P) e parênquima axial subdividido com cristais prismáticos, formando uma série cristalífera (setas). 

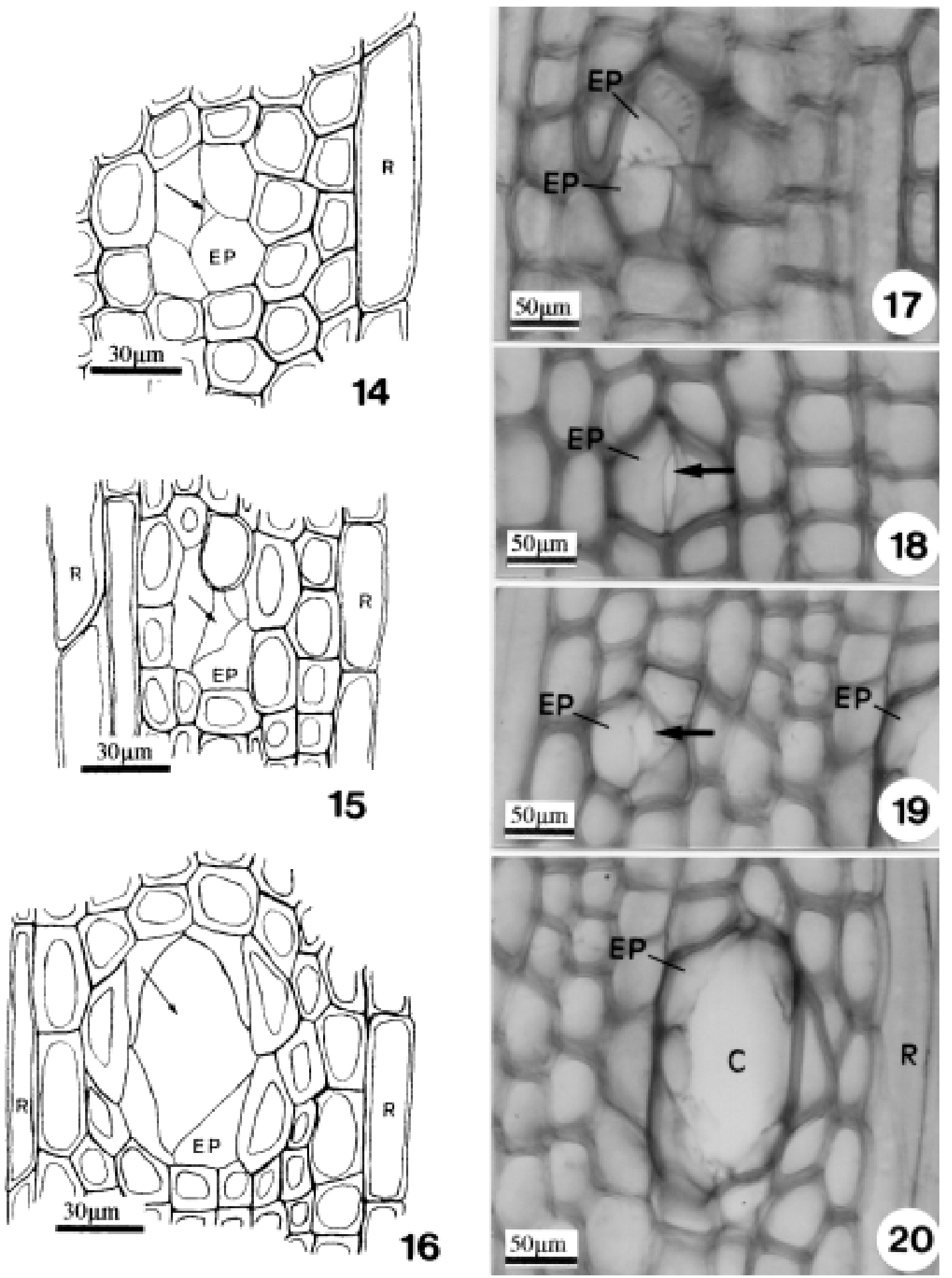

Figuras 14-20. Formação do canal axial. Seções transversais. 14. Espaço intercelular (seta), entre quatro células epiteliais (EP), indicando início de formação do canal axial. Célula do raio (R). 15-16. Formação do canal axial (seta), envolvido por células epiteliais (EP). Célula do raio (R). 17. Células epiteliais (EP), justapostas. 18-20. Espaço intercelular (seta), indicando o início de formação de um canal axial, envolvido por células epiteliais (EP). 20. Canal axial já formado (C) envolvido por células epiteliais (EP) íntegras. Célula do raio (R). 
Os raios são predominantemente multisseriados e variam de 2 a 5 células de largura, predominando os de 3 células, sua altura variando de 5 a 31 células, predominando os de 12 a 16 células (figuras 2,5,11). Os raios unisseriados são raros, de 2 a 16 células de altura, predominando os de 5 a 7 células (figuras 2, 11). São heterogêneos com células quadradas nas margens e células centrais procumbentes (figura 3 ).

Os cristais prismáticos estão presentes em células do parênquima axial subdividido (figura 11) formando séries cristalíferas com até 11 cristais por série (figuras 12,13).

Os resultados quantitativos dos elementos celulares para os dois ambientes estão relacionados na tabela 2. Os nove parâmetros mensurados para este trabalho foram analisados estatisticamente através do teste de Tukey, sendo encontradas diferenças significativas $(\mathrm{p}<0,05)$ entre os ambientes apenas quanto ao diâmetro de vaso - maior nos espécimes do cerradão, e ao diâmetro da pontoação intervascular - maior nos espécimes da floresta.

Os mesmos resultados, quanto a presença de vasos maiores em espécies de cerrado, foram encontrados por Ceccantini (1996) e Mina-Rodrigues (1986), comparando, respectivamente, o lenho de Casearia sylvestris e Pera glabrata de cerrado e de floresta.

Segundo Baas et al. (1983), vasos de maior diâmetro são mais eficientes, porém menos seguros devido ao maior risco de aparecimento de bolhas. Ainda, segundo os mesmos autores, as espécies de ambientes xéricos tendem a reunir os fatores segurança e eficiência, aumentando a freqüência de vasos de menor diâmetro, ou ainda apresentando concomitantemente vasos de diâmetros diferentes. Como mencionado anteriormente, os espécimes de cerradão estudados apresentaram maior diâmetro de vaso do que os indivíduos da floresta. Porém, os mesmos apresentaram também maior freqüência de vasos múltiplos. Machado et al. (1997), estudando Styrax camporum observaram maior diâmetro tangencial dos vasos na raiz em comparação com o caule, sugerindo que o maior diâmetro esteja relacionado à eficiência na condução de água e sais nas raízes.

Com relação às pontoações intervasculares, não foram encontradas informações na literatura consultada relacionando o seu diâmetro tangencial com o ambiente. A ausência de considerações sobre diâmetro tangencial de pontoação intervascular na literatura deve-se ao fato desta ser uma característica considerada por muitos pesquisadores, como conservativa para espécie, gênero ou mesmo família e ordem.

Deve-se salientar que as outras características anatômicas não apresentaram diferenças significativas entre os ambientes, provavelmente devido ao fato do cerradão ser um ambiente de transição entre floresta e cerrado. Por ser uma área de transição, as características que definem um cerrado, estão amenizadas, não influenciando de forma marcante a anatomia da espécie estudada.

Agradecimentos - Agradecemos à FAPESP pelo apoio financeiro (processo $n^{\circ} 98 / 06213-4$ ), ao senhor Antonio Carlos Franco Barbosa que auxiliou na confecção dos cortes histológicos, ao Dr. José Luiz Chiaradia Gabriel pelas identificações taxonômicas e ao técnico Aparecido Agostinho Arruda (Dicão) pelo auxílio nas coletas.

\section{Referências bibliográficas}

ALVES, E.S. \& ANGYALOSSY-ALFONSO, V. 2000. Ecological trends in the wood anatomy of some Brazilian species. I: Growth rings and vessels. IAWA Journal 21:3-30.

BAAS, P. 1973. The anatomy of Ilex (Aquifoliaceae) and its ecological and phylogenetic significance. Blumea 21:193258.

BAAS, P. \& CARLQUIST, S. 1985. A comparison of the ecological wood anatomy of the floras of southern California and Israel. IAWA Bulletin 6:349-353.

BAAS, P., WHEELER, E. \& FAHN, A. 1983. Some ecological trends in vessel characters. IAWA Bulletin 4:141-159.

BAAS, P. \& SCHWEINGRUBER, F.H. 1987. Ecological trends in the wood anatomy of trees, shrubs and climbers from Europe. IAWA Bulletin 8:245-274.

BARAJAS-MORALES, J. 1985. Wood structural differences between trees of two tropical forests in México. IAWA Bulletin 6:355-364.

BICUDO, L.R.H., CESAR, O. \& MONTEIRO, R. 1996. Florística comparativa de uma área de cerrado no município de Botucatu, SP (Brasil). Arquivos de Biologia e Tecnologia 39:685-691.

CARLQUIST, S. 1975. Ecological strategies in xylem evolution. University of California Press, Berkeley.

CARLQUIST, S. 1982. Wood anatomy of Illicium (Illiciaceae). Phylogenetical, ecological and functional interpretations. American Journal of Botany 69:1587-1598.

CARLQUIST, S. 1983. Wood anatomy of Onagraceae: further species; root anatomy; significance of vestured pits and allied structures in dicotyledons. Annals of the Missouri Botanical Garden 69:755-769.

CARLQUIST, S. 1988. Comparative wood anatomy systematic ecological and evolutionary aspects of dicotyledonean wood. Springer Verlag, Berlin.

CARLQUIST, S. \& HOEKMAN, D.A. 1985. Ecological wood anatomy of the woody southern Californian flora. IAWA Bulletin 6:319-347. 
CARVALHO, W.A., PANOSO, L.A. \& MORAES, M.H. 1991. Levantamento semidetalhado dos solos da Fazenda Experimental Edgardia - município de Botucatu. Boletim Científico da Faculdade de Ciências Agronômicas da UNESP, Botucatu.

CECCANTINI, G. 1996. Anatomia ecológica do lenho de espécies de cerrado e mata: Casearia sylvestris $\mathrm{Sw}$. e Machaerium villosum Vog. Dissertação de mestrado, Universidade de São Paulo, São Paulo.

DÉTIENNE, P. \& JACQUET, P. 1983. Atlas d'identification des bois de I'Amazonie et régions voisines. Centre Technique Forestier Tropical, Nogent-sur-Marne.

ESAU, K. 1974. Anatomia das plantas com sementes. Editora da Universidade de São Paulo, São Paulo.

FRANKLIN, G.L. 1945. Preparation of thin sections of synthetic resins and wood-resin composites, and a new macerating method for wood. Nature 155:51.

IAWA COMMITTEE. 1989. International Association of Wood Anatomists. List of microscopic features for hardwood identification. IAWA Bulletin 10:220-332.

JANKOWSKY, I.P., CHIMELO, J.P., CAVALCANTE, A.A., GALINA, I.C.M. \& NAGAMURA, J.C.S. 1990. Madeiras Brasileiras. Spectrum, Caxias do Sul, v.1.

KÖEPPEN, W. 1931. Climatologia. Fondo de Cultura Econômica, Buenos Aires.

KROPP, U. 1972. Leitbündel. Mikrokosmos 61:342-345.
MACHADO, S.R., ANGYALOSSY-ALFONSO, V. \& MORRETES, B.L. 1997. Comparative wood anatomy of root and stem in Styrax camporum (Styracaceae). IAWA Journal 18:13-25.

MAINIERI, C. \& CHIMELO, J.P. 1989. Fichas de características das madeiras brasileiras. Companhia de Promoção de Pesquisa Científica e Tecnológica do Estado de São Paulo, São Paulo.

MINA-RODRIGUES, E.M.C. 1986. Estudo morfo-anatômico dos órgãos vegetativos de Pera glabrata Baill. (Euphorbiaceae), em material procedente de mata mesófila semidecídua e de cerrado. Dissertação de mestrado, Universidade Estadual Paulista, Rio Claro.

PAVIANI, T.I. 1978. Anatomia vegetal e cerrado. Ciência e Cultura 30:1076-1086.

RECORD, S.J. \& HESS, R.W. 1943. Timbers of the New World. Yale University Press, New Haven.

RIZZINI, C.T. 1976. Tratado de fitogeografia do Brasil, aspectos sociológicos e florísticos. HUCITEC/EDUSP, São Paulo.

WHEELER, E.A. 1986. Vessels per square millimetre or vessel groups per square millimetre? IAWA Bulletin 7:73-74.

WHEELER, E.A. \& BAAS, P. 1991. A survey of the fossil record for dicotyledonous wood and its significance for evolutionary and ecological wood anatomy. IAWA Bulletin 12:275-332. 